\title{
CONTRATOS INTERNACIONAIS DE TRANSFERÊNCIA DE TECNOLOGIA E A LEI 12.529/2011: UMA ANÁLISE QUANTO AO CONTROLE DE CONCORRÊNCIA NOS CASOS DA EMPRESA ESTADUNIDENSE MONSANTO.
}

\section{INTERNATIONAL CONTRACTS OF TECHNOLOGY TRANSFER AND THE LAW 12.529/2011: AN ANALYSIS ON THE CONCURRENCY CONTROL IN CASES OF THE AMERICAN COMPANY MONSANTO.}

\author{
${ }^{1}$ Marcelo Markus Teixeira \\ ${ }^{2}$ Rafael Alfredo Weber Hoss
}

\section{RESUMO}

A expansão atual do comércio se deve, sobretudo, a facilidade das negociações em âmbito internacional tendo, como resultado, as mais diversas transações com produtos oriundos de outros países. O mesmo ocorre com a compra e venda da tecnologia, trazendo desenvolvimento econômico nesse diapasão. Porém, por mais que objetive a troca de conhecimento em âmbito internacional, alguns contratos de transferência de tecnologia acabam sendo utilizados, de forma mascarada, para tentar conquistar o domínio de mercado de determinado ramo e obstar a inovação e desenvolvimento econômico, eis que o detentor da tecnologia pode negociá-la com quem lhe convir. A atuação estatal como forma de controle das ações dos sujeitos internacionais pode auxiliar a coibir tal prática, garantindose assim um mercado aberto, com o devido direito à livre concorrência. Contudo, a Lei 12.529/2011 não determina a notificação do Conselho Administrativo de Defesa Econômica (CADE) quando da formalização desses contratos. A fim de compreender como é feito o controle de concorrência ante os casos não obrigatórios de submissão de análise dos contratos e o posicionamento do CADE após a criação da lei, far-se-á uma breve análise de julgados envolvendo contratos internacionais de transferência de tecnologia e domínio de mercado envolvendo a empresa estadunidense Monsanto. Para tanto, a metodologia utilizada será analítica de cunho exploratório.

Palavras-chave: Contratos internacionais, Transferência de tecnologia, Domínio de mercado, Livre concorrência

\begin{abstract}
The current expansion of trade is due, mainly, to ease negotiations at the international level with, as a result, several transactions with products from other countries. The same applies to the purchase and sale of technology, bringing economic development in this tuning fork. But however that aims to exchange knowledge internationally, some technology transfer contracts are eventually used in masked form, to try to conquer the market dominance of particular branch and hinder innovation and economic development, behold, the holder technology can negotiate it with who him agree. The state action as a way to control the actions of international subjects can help restrain this practice, ensuring it is an open market, with due right to free competition. However, the Law 12.529/2011 does not determine the notification of the Administrative Council for Economic Defense (CADE) when the formalization of the contracts. In order to understand how it is done concurrency control in non-binding analysis of cases of submission of contracts and the placement of CADE after the creation of the law, we will briefly tried analysis involving international contracts of technology transfer and market dominance involving the american company Monsanto. For this pourpose, the methodology used is exploratory analytics.
\end{abstract}

Keywords: International contracts, Technology transfer, Market dominance, Free competition

${ }^{1}$ Doutor em Direito Internacional Privado pela Universität Zu Köln, UK, (Alemanha). Professor Permanente do Mestrado Acadêmico em Direito da UNOCHAPECÓ. E-mail: marcelomarkus @ unochapeco.edu.br (Brasil).

${ }^{2}$ Mestrando em Direito pela Universidade Comunitária da Região de Chapecó - UNOCHAPECO, (Brasil). Analista de Projetos no Núcleo de Inovação e Transferência Tecnológica da Unochapecó. E-mail: rafa hoss@ @otmail.com 


\section{1) INTRODUÇÃO}

Em tempos onde a tecnologia torna-se a essência de uma nova sociedade, diariamente somos apresentados a invenções de inegável caráter econômico. Desenvolver ou incentivar a busca por novas tecnologias pode atualmente significar a representatividade de determinado ator internacional na economia mundial.

Por sua vez, a inovação também é objetivo dos próprios países, os quais fomentam a sua prática. No Brasil, por exemplo, o incentivo a inovação está elencado na Constituição Federal, em seus artigos $218^{1}$ e $219^{2}$, estabelece que o Estado promoverá e incentivará o desenvolvimento científico, a pesquisa tecnológica e a capacitação tecnológica

Assim sendo, o ser humano vive desde seus primórdios em um sistema de comércio, posto que individualmente não é capaz de desenvolver tudo que necessita para sua subsistência. O mesmo, consequentemente, ocorre no caso da tecnologia, onde, por variáveis motivos (como a falta de recursos, conhecimentos técnicos, incentivos fiscais, dentre outros) acaba optando pela compra de tecnologia desenvolvida por outros indivíduos. Nessa perspectiva, podemos analisar o caso das empresas sediadas em países menos desenvolvidos que necessitam buscar tecnologia necessária para as pesquisas e desenvolvimento de produtos em países onde esta seja produzida, de forma a propiciar a sua participação nos processos mundiais de inovação científica e tecnológica. Dessas relações comerciais, surgem os contratos de transferência de tecnologia, os quais têm como objeto o desenvolvimento de inovações tecnológicas, ou a exploração temporária de direitos de propriedade industrial, além de outras possibilidades.

Em contraponto, o artigo $170^{3}$ da Constituição Federal, ao versar sobre os princípios gerais que envolvem a atividade econômica, determina que deve ser observado, dentre outros princípios, o princípio da livre concorrência (inciso IV).

1 BRASIL. Constituição Federal de 1988. Art. 218. O Estado promoverá e incentivará o desenvolvimento científico, a pesquisa, a capacitação científica e tecnológica e a inovação.

2 BRASIL. Constituição Federal de 1988. Art. 219. O mercado interno integra o patrimônio nacional e será incentivado de modo a viabilizar o desenvolvimento cultural e sócio-econômico, o bem-estar da população e a autonomia tecnológica do País, nos termos de lei federal.

${ }^{3}$ BRASIL. Constituição Federal de 1988. Art. 170. A ordem econômica, fundada na valorização do trabalho humano e na livre iniciativa, tem por fim assegurar a todos existência digna, conforme os ditames da justiça social, observados os seguintes princípios: I - soberania nacional; II - propriedade privada; III - função social da propriedade; IV - livre concorrência; V - defesa do consumidor; VI defesa do meio ambiente; VI - defesa do meio ambiente, inclusive mediante tratamento diferenciado 
Assim, há que se ter atenção para que os sujeitos internacionais não se tornem dominantes do mercado, podendo assim estabelecer padrões de mercado acima do normal, já que, em caso de domínio de mercado, o principal prejudicado é o próprio cidadão, que, por depender daquela tecnologia, acaba tendo que arcar com as consequências.

A fim de se tentar coibir e controlar a prática de tais atos de concentração é que incide uma das atuações do Conselho Administrativo de Defesa Econômica (CADE), regulamentado pela Lei 12.529/2011, órgão que compõe o Sistema Brasileiro de Defesa da Concorrência (SBDC). Essa legislação, contudo, trouxe novos critérios para o controle concorrencial, se comparada com a Lei 8.884/1994, bem como alterou a necessidade de submissão dos contratos de transferência de tecnologia ao CADE para que seja verificada a existência de eventuais cláusulas contratuais que tendam a ocasionar o domínio de mercado na tecnologia negociada entre as partes contratantes. Com base nessa atuação de controle, o órgão manifestou decisões, posicionamentos e orientações sobre a temática. Assim, pretendese analisar os casos onde o controle de concorrência foi realizado nos contratos de transferência de tecnologia pelo CADE. Para tanto, faremos um estudo sobre os casos que envolveram a empresa estadunidense Monsanto S.A., eis que causaram intensos debates dentro do órgão.

A metodologia a ser utilizada na produção do artigo é analítica de cunho exploratório, baseada na consulta de fontes secundárias, como textos bibliográficos e científicos, bem como serão realizados estudos de casos referentes às tentativas de domínio de mercado no que tange a conflitos decorrentes de transferência de tecnologia.

\section{2) O DESENVOLVIMENTO ATRAVÉS DO VIÉS TECNOLÓGICO}

Desde o fim da década de 70, denota-se uma relativa mudança nas relações entre ciência, tecnologia e atividade industrial. A tecnologia começa a ser considerada como um fator de competitividade dentro do mercado, sendo ainda muitas vezes decisivos e determinantes dentro do sistema industrial. Tecnologia e ciência passaram a direcionar as pesquisas desenvolvidas industrialmente, passando, na maioria dos casos, a ter uma finalidade

conforme o impacto ambiental dos produtos e serviços e de seus processos de elaboração e prestação; VII - redução das desigualdades regionais e sociais; VIII - busca do pleno emprego; IX - tratamento favorecido para as empresas brasileiras de capital nacional de pequeno porte. IX - tratamento favorecido para as empresas de pequeno porte constituídas sob as leis brasileiras e que tenham sua sede e administração no País. 
competitiva, alterando inclusive as condutas concorrenciais das empresas (CHESNAIS, 1996, p. 142-43).

Segundo Chesnais (1996, p. 142):

O exemplo mais claro é, evidentemente, o da biotecnologia, onde "as ciências da vida" estão em ligação quase direta com os processos industriais. Paralelamente, todas as tecnologias críticas contemporâneas caracterizam-se por sua alta capacidade de difusão intersetorial. Elas oferecem oportunidades de renovas a concepção de muitos produtos e inventar novos. Mais importante ainda: exigem a transformação dos processos dominantes de fabricação, bem como das técnicas de gestão, em todo o sistema industrial.

Essa característica de expansão tecnológica é ligada diretamente a sociedade de conhecimento. Essa sociedade de conhecimento pode ser tida como aquela fundada no "compartilhamento de recursos, na construção coletiva de conhecimento, na interação livre de restrições de espaço e tempo e, na valorização do direito à informação, às tecnologias de informação e comunicação e à educação, como um bem comum" (DZIEKANIAK; ROVER. 2011).

Ainda, na visão de Khan (2011):

O conceito de — sociedade da informação, ao meu ver, está relacionado à ideia da -inovação tecnológica, enquanto o conceito de —sociedades do conhecimento inclui uma dimensão de transformação social, cultural, econômica, política e institucional, assim como uma perspectiva mais pluralista e de desenvolvimento. O conceito de - sociedades do conhecimentoll é preferível ao da — sociedade da informaçãoll já que expressa melhor a complexidade e o dinamismo das mudanças que estão ocorrendo. [...] $\mathrm{O}$ conhecimento em questão não só é importante para o crescimento econômico, mas também para fortalecer e desenvolver todos os setores da sociedade.

O direito, assim como outras áreas do conhecimento, também tem se voltado para a importância do desenvolvimento, buscando determinar de que forma a ordem jurídica pode auxiliar na sua promoção. Munhoz (2006, p. 89) explica que o direito constitui um elemento importante na promoção do desenvolvimento, mas também pode ir contra o processo quando a ordem jurídica coloca empecilhos, seja na ordem econômica, política ou social. O direito de concorrência, especificamente, produz impactos diretos sobre o mercado quando garante a existência de um processo competitivo.

O avanço tecnológico iminente da Sociedade de Informação não se desenvolve dissociado da ordem econômica. Basso (2000, p. 21-2) explica que a propriedade intelectual, quando analisada apenas sob a ótica do direito interno, é diferente dos demais ramos do 
direito, pois seu reconhecimento é mais trabalhoso e, sendo que por essa razão, deve-se "somar ao estudo do direito interno o do direito internacional, cujas fontes revigoram constantemente a matéria".

Segundo Aranha (1999, p. 29):

O Direito da Propriedade Intelectual refere-se a proteção dos bens materiais das criações das invenções. Protege-se tudo que é criado pela inteligência do ser humano. Para proteger tudo o que é considerado como Direito de Propriedade Intelectual existem, hoje em dia, mais de vinte tratados internacionais que regulam ou estabelecem princípios sobre a matéria. São tratados que cobrem uma série de subdivisões da propriedade intelectual.

Historicamente, a proteção da produção baseada em capital intelectual começou com Convenção de Paris, realizada em 1883. Com fins de proteção da propriedade industrial, foi aprovada exatamente pelo fato de começar a existir naquele século uma internacionalização do sistema de propriedade industrial. Dentre os princípios oriundos da Convenção, estão o princípio do tratamento nacional da não discriminação e a proteção contra os atos de concorrência desleal, os quais tentam garantir a existência de um comércio mais aberto, e, além de tudo, mais justo. (ARANHA, 1999, p. 30).

A proteção contra a concorrência desleal na Convenção de Paris, já com a revisão de Estocolmo, em 1975, quando na oportunidade foi criada a Organização Mundial de Propriedade Intelectual (OMPI), está prevista no artigo $10^{\circ}$, bis, o qual dispõe que “os países da União obrigam-se a assegurar aos nacionais dos países da União proteção efetiva contra a concorrência desleal", classificando o ato de concorrência desleal como "qualquer ato de concorrência contrário aos usos honestos em matéria industrial ou comercial".

Após essas medidas, houve ainda a Rodada no Uruguai do General Agreement on Tarifs and Trade (GATT, também conhecido como Acordo Geral de Tarifas e Comércio), em 1994, onde as discussões sobre a tutela da propriedade intelectual ganharam destaque, estabelecendo-se regras sobre a propriedade intelectual ligadas ao comércio, sendo que o documento oriundo da rodada foi anexado ao Tratado Constitutivo da Organização Mundial do Comércio (OMC), criada no mesmo ano (WACHOWICZ, 2007, p. 76).

Dentro do acordo constitutivo da OMC, encontramos o Anexo 1. C, nomeado como Acordo sobre aspectos dos direitos de propriedade intelectual relacionados ao comércio, conhecido pela sigla TRIPS. Segundo Basso (2000, p. 192), a inclusão do TRIPS na OMC se deve por duas razões: "o interesse de completar as deficiências do sistema de proteção da 
propriedade intelectual da OMPI, e a segunda, a necessidade de vincular, definitivamente, o tema ao comércio internacional".

Para Wachowicz (2007, p. 76-7):

\begin{abstract}
A discussão sobre o conjunto internacional de regras mínimas que haverão de ser aplicadas em todos os Estados membros da OMPI e OMC, como meio de tutelar a propriedade intelectual e seu desenvolvimento no mundo, torna- se imprescindível e inevitável. De igual modo, faz-se mister analisar a relevância dos impactos que o progresso tecnológico da informação pode gerar para o ser humano e as comunidades em geral, ora incluindo-se nessa nova Sociedade de Informação, ao possibilitar seu acesso aos bancos de dados, ora excluindo-os, quando estes, por questões econômicas ou políticas, não tenham acesso a informação. Neste sentido, é imperioso investigar os caminhos que o Direito terá de percorrer para permitir que, de uma forma justa e equitativa, os fornecedores de serviços, os titulares de propriedade intelectual e os utilizadores, a sociedade civil, de modo geral, possam se beneficiar desse novo universo digital.
\end{abstract}

Já em âmbito nacional, a Constituição Federal, em seus artigos $218^{4}$ e $219^{5}$, estabelece que o Estado promoverá e incentivará o desenvolvimento científico, a pesquisa tecnológica e a capacitação tecnológica, além de viabilizar o desenvolvimento cultural e socioeconômico, o bem-estar da população e a autonomia tecnológica do País, nos termos da lei federal.

A propriedade intelectual, por sua vez, em âmbito nacional, é considerada um direito fundamental, prevista no artigo $5^{\circ}$, nos incisos $\mathrm{XXVII}^{6}$ e $\mathrm{XXIX}^{7}$ da $\mathrm{CF} / 88$, a qual é limitada pelos direitos inerentes a propriedade e princípios de ordem econômica.

Em matéria infraconstitucional, a Propriedade Intelectual no Brasil é regulamentada pela Lei 9.279, de 1996, a qual trata de características e procedimentos de proteção de direitos

4 BRASIL. Constituição Federal de 1988. Art. 218. O Estado promoverá e incentivará o desenvolvimento científico, a pesquisa, a capacitação científica e tecnológica e a inovação.

${ }^{5}$ BRASIL. Constituição Federal de 1988. Art. 219. O mercado interno integra o patrimônio nacional e será incentivado de modo a viabilizar o desenvolvimento cultural e sócio-econômico, o bem-estar da população e a autonomia tecnológica do País, nos termos de lei federal.

${ }^{6}$ BRASIL. Constituição Federal de 1988. Art $5^{\circ}$ - Todos são iguais perante a lei, sem distinção de qualquer natureza, garantindo-se aos brasileiros e aos estrangeiros residentes no País a inviolabilidade do direito à vida, à liberdade, à igualdade, à segurança e à propriedade, nos termos seguintes: [...] XXVII - aos autores pertence o direito exclusivo de utilização, publicação ou reprodução de suas obras, transmissível aos herdeiros pelo tempo que a lei fixar;

${ }^{7}$ BRASIL. Constituição Federal de 1988. Art $5^{\circ}$ [...] XXIX - a lei assegurará aos autores de inventos industriais privilégio temporário para sua utilização, bem como proteção às criações industriais, à propriedade das marcas, aos nomes de empresas e a outros signos distintivos, tendo em vista o interesse social e o desenvolvimento tecnológico e econômico do País; 
inerentes a propriedade industrial, posto seu interesse social e benefícios ao desenvolvimento tecnológico e econômico do País.

\section{3) A INOVAÇÃO ABERTA}

Nesse meio de sociedade de conhecimento, com foco na inovação tecnológica, surge o modelo de inovação aberta, eis que, por vezes, o alavancar de produtos e pesquisas depende da cessão ou troca de resultados e ideias.

Segundo o Manual de Oslo $^{8}$, a Inovação consiste na "implementação de um produto (bem ou serviço) novo ou significativamente melhorado, ou um processo, ou um novo método de marketing, ou um novo método organizacional nas práticas de negócios, na organização do local de trabalho ou nas relações externas" (OCDE, 1997, p. 55). Outrossim, uma inovação pode ser categorizada em virtude da implementação de um ou mais tipos de inovação, por exemplo inovações de produto e de processo.

Inovação aberta, por sua vez, corresponde à utilização de ideias externas, e deixar que as ideias e tecnologias não aproveitadas sejam utilizadas por outras organizações, fazendo com que ocorra a troca de informações de caráter tecnológico. Isso exige que cada empresa ao abrir o seu modelo de negócio permita que fluam ideias e tecnologias externas de fora para dentro e que mais conhecimento interno flua de dentro para fora. A inovação aberta oferece a perspectiva de custos para a inovação mais baixos, menor tempo para entrar no mercado e a possibilidade de dividir riscos com outras empresas (CHESBROUGH, 2012). Representa assim um meio de efetivação de desenvolvimento econômico, e possui repercussões diretas na proteção dos direitos de propriedade intelectual e transferência de tecnologia.

A inovação, segundo Mattos e Guimarães (2012, p. 63) consiste em duas etapas, as quais compreendem a invenção (primeira etapa) e a comercialização da invenção (segunda etapa), posto que a tecnologia é uma mercadoria, muitas vezes produzida intencionalmente. Segundo os autores, a tecnologia tem proprietário, que, por ser detentor de direitos da patente, pode vender, trocar e ceder seus conhecimentos.

De acordo com Silva (2012):

${ }^{8}$ O Manual de Oslo consiste em uma orientação editada pela Organização para a Cooperação e Desenvolvimento Econômico (OCDE) que tem o objetivo de orientar e padronizar conceitos, metodologias e construção de estatísticas e indicadores de pesquisa de Pesquisa e Desenvolvimento de países industrializados. 


\begin{abstract}
O comércio internacional diz respeito à compra e venda de bens e serviços, especialmente entre países, com a particularidade de o comércio internacional envolver, regra geral, a utilização de diversas moedas e estar sujeito a regulamentações adicionais, tais como tarifas, quotas e controlos cambiais. O comércio internacional compreende quatro grandes categorias: as mercadorias, isto é, todos os bens materiais, como géneros alimentícios, vestuário, matérias primas e maquinaria; os serviços, que abrangem produtos como o turismo, os serviços bancários e as telecomunicações; a propriedade intelectual, que diz respeito ao comércio e investimento em ideias e criatividade (direitos de autor, design industrial, direitos dos artistas, etc..) e o investimento que ocorre quando, por exemplo, uma empresa de um país cria uma empresa de raiz ou adquire uma empresa, outro país.
\end{abstract}

Além disso, Moredo (2012, p. 299-301) explica que dentro da sociedade que objetiva seu desenvolvimento econômico podemos encontrar o viés da tecnologia, sendo que essas tecnologias almejam a solução de problemas ou a criação de oportunidades. O que, segundo o autor, deve ser analisado, independentemente do local onde seja gerada a tecnologia, é o retorno financeiro desejado, pois há que se pensar no mercado de negócios. Assim, a tecnologia consiste em "um ativo intangível que se opera com o objetivo de obter num futuro próximo um retorno sobre o mesmo".

A transação desse ativo intangível se dá por meio de contratos de transferência de tecnologia, que envolvem o direito de propriedade. Assim, as empresas conseguem uma melhor posição de mercado, eis que, conforme Mattos e Guimarães (2005, p. 18), “a tecnologia é provavelmente o mais importante fator para o aumento da competitividade global de uma empresa".

\title{
4) CONTRATOS DE TRANSFERÊNCIA DE TECNOLOGIA E DOMÍNIO DE MERCADO
}

Como sabemos, os avanços tecnológicos são constantes e diários, podendo até ser classificados como uma era da revolução tecnológica. A economia tem sofrido grandes influências positivas quando tratamos de tecnologia, principalmente por fazer parte de um mercado em plena expansão e que não tende a deixar de crescer, com mudanças significativas na própria atividade econômica da empresa, além do fato de toda sociedade depender de seus benefícios. A transferência de tecnologia é uma das formas de viabilização de crescimento dessa área econômica.

A fim de que se possa compreender o conceito de contrato de transferência de tecnologia internacional, necessário é definir separadamente o contrato internacional e a transferência de tecnologia. 
Strenger (1992, p. 81) apresenta a seguinte definição para os contratos internacionais:

São contratos internacionais do comércio, todas as manifestações bi ou plurilaterais da vontade livre das partes, objetivando relações patrimoniais ou de serviços, cujos elementos sejam vinculantes de dois ou mais sistemas jurídicos extraterritoriais, pela força do domicílio, nacionalidade, sede principal dos negócios, lugar do contrato, lugar da execução, ou qualquer circunstância que exprima um liame indicativo de Direito aplicável.

Strenger (1992, p. 23-4), ao definir as características de contratos internacionais, destaca as observações de José Maria Espinar Vicente, o qual as elenca como sendo as principais:

a) são contratos que desenvolvem o intercâmbio de mercadorias, serviços e capitais, entre empresas pertencentes a diferentes países; b) são contratos nos quais ao menos uma das partes desempenha papel preponderante no meio econômico internacional, no que concerne a matéria objeto do acordo; c) são contratos que - devido a concentração oligopolista dos bens e a atual estrutura do comércio mundial - não só afetam aos Estados diretamente conectados à operação que instrumentalizam, mas a todos os países que integram a área do mercado dos bens ou serviços aos quais se referem; d) são contratos que - em razão da organização transnacional dos poderes econômicos privados - põem em jogo, direta ou indiretamente, os interesses corporativos do conjunto de empresas que se dediquem habitualmente ao setor de atividades em que se inclua a operação; e) normalmente, a forma desses contratos responde a caracteres peculiares, entre os quais se destacam: a homogeneidade de suas disposições, a existência de cláusulas de submissão, a arbitragem e o emprego de terminologia unificada. A qualificadora econômico não altera, na substancialidade, o nome genérico de contratos internacionais, porquanto será difícil desconstituir o escopo das negociações do comércio mundial o aspecto econômico [...].

Já para Baptista (2011, p. 28-30), o contrato pode ser considerado como sendo internacional quando seus elementos possibilitarem a sua vinculação a mais de um sistema jurídico, que em seu objeto geram um duplo fluxo de bens pela fronteira, ou que decorrem diretamente de contrato dessa natureza. Tal constatação parte da própria legislação brasileira, citando como exemplo o Decreto-Lei 857, de 1969, o qual estabelece que em negócios celebrados entre residentes e não-residentes pode-se utilizar moeda estrangeira, pois esse negócio teria um caráter internacional, considerando a importância que tem o lugar e a moeda do pagamento em um contrato. Destaca ainda o autor que os contratos internacionais podem trazer diversas consequências.

Por sua vez, Zaitz (2005, p. 113), ao definir o conceito de transferência de tecnologia internacional, explica que: 
a expressão "transferência internacional de tecnologia", no âmbito da prática contratual, serve para denominar grande parte dos contratos que envolvem a comunicação de informação entre diferentes países. Incluem-se nessa categoria contratos de licenciamento de patentes, marcas, contratos de know-how, contratos de prestação de serviços técnicos, dentre outros.

Para Corrêa (2005, p. 96):

Num sentido amplo, a transferência de tecnologia significa um negócio jurídico pelo qual uma das partes obriga-se a transmitir determinados conhecimentos aplicáveis a um processo produtivo, sendo remunerada pela outra parte. Para que haja real transferência de tecnologia é necessária a assimilação dos conhecimentos pelo receptor.

Outrossim, o termo know-how, para Zaitz (2005, p. 113), é utilizado para “designar conhecimentos técnicos (não patenteados) ou comerciais que tenham valor econômico, sejam transmissíveis, sejam secretos ou relativamente secretos [...] e que tragam vantagem competitiva para seu detentor", sendo o contrato um meio de valorização e de circulação do know-how.

A interferência do Estado é bastante restrita no Brasil, sendo que dentre as formas de controle estão a averbação dos contratos de transferência de tecnologia no Instituto Nacional de Propriedade Industrial e a jurisdição do CADE.

Contudo, há que se ter o cuidado para que os sujeitos internacionais não se tornem dominantes do mercado, podendo assim estabelecer padrões de mercado acima do normal, já que, em caso de domínio de mercado, o principal prejudicado é o próprio cidadão, que, por depender daquela tecnologia, acaba tendo que arcar com as consequências.

\section{5) A CRIAÇÃO DA LEI 12.529/2011 E O SISTEMA BRASILEIRO DE DEFESA DA CONCORRÊNCIA (SDBC)}

Em contraponto do incentivo ao desenvolvimento científico e tecnológico, a Constituição Federal dispõe sobre as questões envolvendo a proteção da ordem econômica. $\mathrm{O}$ artigo 170, ao versar sobre os princípios gerais que envolvem a atividade econômica, determina que deve ser observado, dentre outros princípios, o princípio da livre concorrência. Ainda, no $\S 4^{\circ}$ do art. 173, também há a previsão de que “a lei reprimirá o abuso do poder 
econômico que vise à dominação dos mercados, à eliminação da concorrência e ao aumento arbitrário dos lucros".

O Sistema Brasileiro de Defesa da Concorrência (SBDC) é regido pela Lei 12.529/2011, a qual também é responsável por regulamentar os crimes contra a ordem econômica. Conforme disposição do artigo $3^{\circ}$, o SBDC é formado pelo Conselho Administrativo de Defesa Econômica - CADE e pela Secretaria de Acompanhamento Econômico do Ministério da Fazenda-SEAE. O CADE tem as atribuições de analisar e aprovar ou não os atos de concentração econômica, de investigar condutas prejudiciais à livre concorrência e, se for o caso, aplicar punições aos infratores e de disseminar a cultura da livre concorrência. A Seae, por sua vez, realiza a chamada "advocacia da concorrência" perante órgãos do governo e a sociedade.

O controle realizado pelo CADE pode ser feito de duas formas, sendo classificadas como repressivo ou preventivo.

O controle preventivo se dá pela análise dos atos de concentração, que compreendem as operações de fusões de duas ou mais empresas anteriormente independentes, as aquisições de controle ou de partes de uma ou mais empresas por outras, as incorporações e associações de qualquer espécie entre agentes econômicos. Como ato de concentração, o artigo 90 prevê:

Art. 90. Para os efeitos do art. 88 desta Lei, realiza-se um ato de concentração quando: I - 2 (duas) ou mais empresas anteriormente independentes se fundem; II - 1 (uma) ou mais empresas adquirem, direta ou indiretamente, por compra ou permuta de ações, quotas, títulos ou valores mobiliários conversíveis em ações, ou ativos, tangíveis ou intangíveis, por via contratual ou por qualquer outro meio ou forma, o controle ou partes de uma ou outras empresas; III - 1 (uma) ou mais empresas incorporam outra ou outras empresas; ou IV - 2 (duas) ou mais empresas celebram contrato associativo, consórcio ou joint venture. Parágrafo único. Não serão considerados atos de concentração, para os efeitos do disposto no art. 88 desta Lei, os descritos no inciso IV do caput, quando destinados às licitações promovidas pela administração pública direta e indireta e aos contratos delas decorrentes.

Quanto a obrigatoriedade de análise dos casos de atos de concentração econômica, o artigo 88 estabelece que será necessário submeter a convalidação do negócio ao CADE quando pelo menos um dos grupos envolvidos na operação tenha registrado, no último balanço, faturamento bruto anual ou volume de negócios total no País, no ano anterior à operação, equivalente ou superior a $\mathrm{R} \$ 400$ milhões (inciso I) e quando pelo menos um outro grupo envolvido na operação tenha registrado, no último balanço, faturamento bruto anual ou volume de negócios total no País, no ano anterior à operação, equivalente ou superior a $\mathrm{R} \$ 30$ 
milhões (inciso II). Os $\S 5^{\circ}$ e $6^{\circ}$ do mesmo artigo destacam ainda que serão proibidos os atos de concentração que impliquem eliminação da concorrência em parte substancial de mercado relevante, que possam criar ou reforçar uma posição dominante ou que possam resultar na dominação de mercado relevante de bens ou serviços, ressalvados os casos quando cumulada ou alternativamente aumentar a produtividade ou a competitividade, melhorar a qualidade de bens ou serviços ou propiciar a eficiência e o desenvolvimento tecnológico ou econômico, e, sejam repassados aos consumidores parte relevante dos benefícios decorrentes. Por ser um controle considerado prévio, os atos não poderão ser praticados antes da apreciação do órgão.

Por sua vez, o controle repressivo é realizado quando o ato já foi praticado, incorrendo em infração contra a ordem econômica, e tem por objetivo reprimir sua prática. $\mathrm{O}$ artigo 36 da lei elenca os atos que podem ser considerados infração, sendo assim considerados aqueles que, mesmo que não alcancem o objetivo, tendem a limitar, falsear ou de qualquer forma prejudicar a livre concorrência ou a livre iniciativa (inciso I), dominar mercado relevante de bens ou serviços (inciso II), aumentar arbitrariamente os lucros (inciso III) e exercer de forma abusiva posição dominante (inciso IV).

Lilla (2014, p. 95), explica que podemos elencar as seguintes infrações previstas no artigo $36, \S 3^{\circ}$, que podem envolver a transferência de tecnologia:

(i) impedir o acesso de concorrente às fontes de insumo, matériasprimas, equipamentos ou tecnologia, bem como aos canais de distribuição (inciso V); (ii) regular mercados de bens ou serviços, estabelecendo acordos para limitar ou controlar a pesquisa e o desenvolvimento tecnológico, a produção de bens ou prestação de serviços, ou para dificultar investimentos destinados à produção de bens ou serviços ou à sua distribuição (inciso VIII); (iii) açambarcar ou impedir a exploração de direitos de propriedade industrial ou intelectual ou de tecnologia (inciso XIV); e (iv) exercer ou explorar abusivamente direitos de propriedade industrial, intelectual, tecnologia ou marca (inciso XIX). A depender de sua configuração, outras condutas listadas também podem configurar ilícitos anticoncorrenciais relacionados à transferência de tecnologia, tais como condutas colusivas (incisos Ie II), recusa de venda (inciso XI) e venda casada (inciso XVIII).

Na vigência da Lei 8.884/94, que foi revogada pela Lei 12.529/2011, em seu artigo 54 previa que "os atos, sob qualquer forma manifestados, que possam limitar ou de qualquer forma prejudicar a livre concorrência, ou resultar na dominação de mercados relevantes de bens ou serviços, deverão ser submetidos à apreciação do CADE”. Comparando-se a redação da atual legislação apresentada anteriormente (artigo 88), percebe-se que a anterior era mais 
geral, o que fazia com que todos os contratos passassem pelo crivo do CADE, o que não mais ocorre.

Pertinente então é o estudo para se verificar como o CADE vem atuando frente a essa alteração quanto à obrigatoriedade de submissão a apreciação nos casos de transferência de tecnologia internacional.

\section{6) CASOS ENVOLVENDO A MONSANTO TRAZEM UMA NOVA PERSPECTIVA PARA O CONTROLE DE CONCORRÊNCIA FRENTE A LEI 12.529/2011}

Mesmo com um número reduzido de decisões relativas ao controle de concorrência em contratos de transferência de tecnologia, o CADE já teve a oportunidade de se manifestar em alguns casos, dentre eles envolvendo a empresa de origem estadunidense Monsanto do Brasil LTDA ("Monsanto"), a qual é controlada pelo Grupo Monsanto.

Essa empresa atua no desenvolvimento de biotecnologia aplicada aos processos produtivos em variedades de sementes, produzindo e comercializando produtos como defensivos agrícolas, sementes e biotecnologia.

Dentre os casos envolvendo a empresa, elencam-se os seguintes, que serão analisados:

a) 08012.002870/2012-38, envolvendo a Monsanto e Syngenta Proteção de Cultivos LTDA, tendo como relator o Conselheiro Marcos Paulo Veríssimo, julgado na $27^{\mathrm{a}}$ Sessão Ordinária de Julgamento, em 28 de agosto de 2013;

b) 08012.006706/2012-08, envolvendo a Monsanto e Nidera Sementes LTDA, tendo como relator o Conselheiro Alessandro Octaviani, julgado na $27^{a}$ Sessão Ordinária de Julgamento, em 28 de agosto de 2013;

c) 08012.003898/2012-34 Monsanto e Cooperativa Central de Pesquisa Agrícola, tendo como relator o Conselheiro Alessandro Octaviani, julgado na $27^{\mathrm{a}}$ Sessão Ordinária de Julgamento, em 28 de agosto de 2013;

d) 08012.003937/2012-01 (Monsanto e Don Mario Sementes), tendo como relator o Conselheiro Alessandro Octaviani e voto-vista do Conselheiro Eduardo Pontual Ribeiro, julgado na $27^{\text {a }}$ Sessão Ordinária de Julgamento, em 28 de agosto de 2013 e;

e) 08700.004957/2013-72, entre Monsanto e Bayer, julgado na 36ª Sessão Ordinária de Julgamento em 22 de janeiro de 2014. 
Nos casos da $27^{\mathrm{a}}$ Sessão Ordinária de Julgamento, os respectivos contratos de transferência de tecnologia envolviam o licenciamento da Monsanto as empresas anteriormente elencadas, de forma não exclusiva, para desenvolvimento, teste, produção e comercialização, no Brasil, de variedades de sementes de soja contendo tecnologia Intacta RR2 $\mathrm{PRO}^{\mathrm{TM}}$, a qual torna a planta resistente a insetos e daria tolerância ao glifosato, além de licenciar a marca Intacta RR2 PRO. Os casos foram analisados inicialmente na $13^{\text {a }}$ Sessão Ordinária de Julgamento, mas houve divergência nos votos com relação ao conhecimento das operações que envolvessem esse tipo de contrato, sendo que o Conselheiro Eduardo Pontual Ribeiro pediu vista dos casos para análise e manifestação.

A Superintendência-Geral do CADE, em oportunidade, na análise do mérito, destacou a inocorrência de alteração na estrutura concorrencial no caso, manifestando a seguinte decisão:

Pelo exposto, entende-se que licenciamentos não-exclusivos de uso de tecnologia, desde que também não carreguem consigo acordos de nãoconcorrência, transferência de ativos, organização comum ou vínculos societários de qualquer natureza, ou qualquer medida que implique em alteração dos centros decisórios ou restrição concorrencial, não são de notificação obrigatória ao CADE nos termos da Lei 12.529/2011 (Parecer 171 da Superintendência-Geral).

O Conselheiro Marcos Paulo Veríssimo, na análise do Ato de Concentração envolvendo a Syngenta, explicou não haver uma jurisprudência consolidada sobre o conhecimento de contratos de licenciamento não exclusivo de patentes, e, que esses contratos, de um ponto de vista jurídico, não teriam capacidade de produzir concentração econômica. Outrossim, as preocupações concorrenciais decorreriam do exercício abusivo do direito de patente, cabendo então o controle repressivo, e que exigir o conhecimento dessas operações faria outras operações similares tornarem-se ilegais, alegando que outras jurisdições como a União Europeia e Estados Unidos dispensavam a notificação desses contratos.

O Conselheiro Alessandro Otaviani, no caso envolvendo a Nidera Sementes LTDA, em síntese, votou pelo conhecimento da operação e que não geraria efeitos anticoncorrenciais, eis que a Nidera possuía uma baixa participação no mercado.

A Conselheira Ana Frazão, em voto de vista sobre as quatro operações, concluiu pelo não conhecimento das mesmas. Além disso, buscou entender o que seria um ato de concentração e onde se encaixaria o contrato de licença de patente sem exclusividade, constatando que esse tipo de contrato não se assemelharia a um contrato associativo, eis que não objetivam uma empresa comum e só demonstra que ambas as empresas estão aptas a 
desenvolver as mesmas atividades, cada uma com seus riscos. Destacou a conselheira que esse tipo de contrato só poderia ser considerado como associativo caso adotasse um sentido amplo de cooperação, sendo necessária uma modificação de estrutura de mercado.

O Conselheiro Elvino Mendonça, também em voto de vista, manifestou que existem diversas formas de controle entre empresas, inclusive nos casos de tecnologia, o que poderia gerar uma relação de dependência entre licenciante e licenciada, apontando que a licença pode ser vista como uma forma associativa. Votou pelo conhecimento da operação por envolver transferência de tecnologia e criação de barreiras à entrada e desincentivo a inovação.

Passa então o Conselheiro Eduardo Pontual a analisar o caso. Inicialmente, apresenta o funcionamento da cadeia produtiva do mercado de sementes de soja geneticamente modificadas, o qual seria (1) desenvolvimento da tecnologia transgênica, (2) desenvolvimento do germoplasma, etapa onde as empresas melhoradoras desenvolvem diferentes variedades de soja, área em que atuam as empresas licenciadas nos Atos de Concentração, (3) multiplicação das sementes, (4) distribuição e comercialização das sementes e (5) por fim, a chegada da semente ao agricultor. Destaca que as cultivares obtidas pelos desenvolvedores, com a autorização para utilização do produto registrado da Monsanto, passam a ser comercializadas através de autorizações, regras e condições específicas a cada empresa.

Em seguida, explica o sistema de royalties da Monsanto, sendo que a mesma os recebe de três formas: a) royalty na semente, que são pagos pelos agricultores; b) royalty no grão, os quais são pagos pelos agricultores na entrega dos grãos nos pontos de entrega, quando não pagos royalties na semente; e c) royalty de multiplicação, pagos pelos multiplicadores. Com isso, o conselheiro observa que mesmo que o contrato de transferência de tecnologia seja apenas para obtenção de variedades, sem a transação de royalties entre a obtentora e a Monsanto, com base nas informações do Ato de Concentração, percebe-se que esses contratos são no caso de licença comercial, não de licenciamento exclusivamente para desenvolvimento, sendo ambos (licenciadas e licenciadora) remunerados pela inovação obtida.

Salienta, em seu voto, que:

Nos presentes casos, os contratos são bastante complexos. Envolvem não só o registro e desenvolvimento de novas variedades, a partir de em contratos de $P \& D$ já realizadas, mas também: multiplicação com pagamento de Royalties; uso por parte da licenciante e licenciada das informações das variedades desenvolvidas pela obtentora; comercialização e regramentos sobre licenciamentos a terceiros multiplicadores por parte da licenciada, além de uso de marcas de propriedade da Monsanto. De modo objetivo, 
entendo que os contratos analisados trazem cláusulas que mostram os esforços para um bem comum, com forma de financiamento do desenvolvimento de produtos de forma conjunta (com venda do cultivar) e com uma influência concorrencial clara nos negócios outros da licenciada que não com a Monsanto.

Isso reflete, conforme o conselheiro, a dominância da Monsanto no mercado de sementes de soja. Igualmente, há outras cláusulas nos contratos que demonstram a existência de solidariedade na busca de um objetivo comum da marca Intacta RR2 PRO e suas variedades, entendendo, com isso, tratar-se de um contrato associativo e que demonstram restrição concorrencial a fim de dominância no mercado de sementes de soja.

Mesmo a Monsanto não utilizando uma cláusula de exclusividade textual, destaca que houve a tentativa de criação de um mecanismo que seguisse a mesma direção, capaz de criar barreiras à entrada no mercado de soja transgênica, gerando graves prejuízos a concorrência.

Por fim, o Conselheiro conheceu as operações e votou pela aprovação com restrições, determinando a alteração de todas as cláusulas que permitiam o controle da Monsanto sobre as licenciadas em decisões comerciais não relacionada à semente com tecnologia da Monsanto.

Após o voto do Conselheiro Eduardo Pontual, os Conselheiros Alessandro Octaviani Luis e a Conselheira Ana Frazão, retificaram os votos anteriormente proferidos e aderiram ao voto do Conselheiro. O Plenário, por maioria, conheceu da operação, vencido o Conselheiro Marcos Paulo Verissimo que votou pelo não conhecimento da operação e, no mérito, por maioria, aprovou-a com restrição às cláusulas que permitam controle da Monsanto sobre as licenciadas em decisões comerciais e societárias não relacionadas à semente com tecnologia da Monsanto, determinando a comprovação das referidas alterações no prazo de 60 dias a contar da publicação da decisão, sendo vencidos o Conselheiro Elvino de Carvalho Mendonça e o Conselheiro Marcos Paulo Verissimo que votaram pela aprovação sem restrições.

Já no julgamento do caso Monsanto e Bayer, o Conselheiro Alessandro Octaviani Luis, em seu voto, explica que a licenciada é controla pelo Grupo Bayer e atua com produtos e serviços ligados ao setor químico, da saúde humana e animal, agricultura, biotecnologia e engenharia para as indústrias químicas e farmacêuticas. Outrossim, defende que os contratos de transferência de tecnologia são capazes de formar uma nova estrutura econômica, e, que a competitividade no segmento de desenvolvimento de tecnologias transgênicas está associada a dois aspectos, sendo eles as estratégias de integração e diversificação das empresas e a realização de contratos de parceria tecnológica. 
Após destacar aspectos econômicos e funcionais da empresa em seu voto, relembra que a empresa "é proprietária da única tecnologia de soja atualmente comercializada no Brasil e tem predominância no mercado de sementes transgênicas, como um todo, as práticas adotadas por essa empresa são, efetivamente, as práticas dominantes no mercado", sendo que os contratos de licenciamento de tecnologia podem funcionar como "atos formalizadores de entreleçamento de interesses comerciais entre agentes econômicos independentes", caracterizando um contrato associativo, conforme prevê o inciso IV do artigo 90.

Por fim, o relator votou pela aprovação do Ato de Concentração, elencando as cláusulas contratuais (que são confidenciais) e o remédio antitruste para cada caso, além de restringir o uso de qualquer cláusula que permita o exercício de influência externa da Monsanto sobre a Bayer.

\section{7) CONCLUSÃO}

O processo de evolução tecnológica vem ganhando forças principalmente nas últimas décadas, trazendo consigo novos produtos e modos de produção, o que consequentemente acarretou em questões mercadológicas, econômicas e principalmente no estilo de vida da população mundial. O atual estágio de globalização permite um fluxo de informações gigantesco e em velocidade até então desconhecidas.

Dentro das relações internacionais, a tecnologia está se tornando reconhecidamente um fator de poder e de influência sobre as práticas de mercado. Tanto o é que passou a ser regulamentada pelo Direito Internacional. A Convenção de Paris representa o início da proteção da propriedade industrial, sendo que ainda à época já se previu a necessidade de proteção contra os atos de concorrência desleal e o tratamento nacional da não discriminação.

Outrossim, a proteção de ativos intangíveis, como é o caso da tecnologia, faz com que se desenvolva e fomente um espírito de competitividade entre os agentes econômicos, que buscam desenvolver ou aprimorar seus produtos, de forma a garantir ainda mais benefícios aos consumidores, além de atender as suas principais necessidades. Perceptível então é a importância da propriedade industrial dentro do atual cenário econômico internacional, devendo ser reconhecida como um fator de crescimento e diferencial dentro do mercado.

A transferência de tecnologia representa, nesse contexto, uma forma de ampliar o desenvolvimento de pesquisas, permitindo que estas se complementem ou mesmo tenham a 
devida aplicação industrial após o seu desenvolvimento, tornando-se um facilitador na troca de informações e conhecimentos de caráter tecnológico.

Destacou-se, porém, que os contratos internacionais de transferência de tecnologia são capazes, por seus meios, de afetar o direito concorrencial, restringindo mercados, o incentivo a inovação e o próprio desenvolvimento tecnológico nacional, cabendo uma atenção especial a esses casos a fim de que se evite o domínio de mercado pelos agentes econômicos com maior poderio.

Como visto, o controle concorrencial realizado pelo CADE, integrante do Sistema Brasileiro de Defesa da Concorrência, durante a vigência da Lei 8.884/94, era mais efetivo, eis que era realizado sobre todos os atos, indiferente de sua forma, que pudessem limitar ou prejudicar a livre concorrência, ou ainda resultar na dominação de um determinado segmento de mercado. Contudo, a alteração trazida pela Lei 12.529/2011 fez com que a atuação do órgão frente a possíveis casos de domínio de mercado, aplicando assim o controle de concorrência, tornassem-se mais restritos.

Após analisarmos os casos envolvendo a empresa estadunidense Monsanto S.A., e, com base nas observações apontadas pelos conselheiros em seus votos, constata-se que os contratos internacionais de transferência de tecnologia podem ter como objetivo a restrição do mercado, criando relações de exclusividade entre os contratantes mesmo sem que haja uma cláusula contratual específica para tanto, os quais unem seus interesses para alcançar um objetivo comum.

Essa perspectiva apresentada nos casos envolvendo a Monsanto S.A. demonstra o risco que os contratos internacionais de transferência de tecnologia representam ao direito concorrencial e a importância que possui o controle de concorrência nos casos de contratos internacionais de transferência de tecnologia. Cabe assim ao CADE, mesmo com a alteração legislativa, manter um controle rigoroso sobre todos os atos, analisando também todas as particularidades inerentes ao contrato, posto que foi por meio dessa análise que o Conselheiro Eduardo Pontual conseguiu identificar a tentativa intrínseca de dominar o mercado de sementes, e, consequentemente, a dependência tecnológica, que pode comprometer o desenvolvimento econômico do país e atingir o principal interessado, o consumidor.

\section{REFERÊNCIAS}

ARANHA, José Graça. Convenções Internacionais em Matéria de Propriedade Industrial. In: Seminários OMPI de Propriedade Intelectual e Mecanismos de Transferência de Tecnologia. Maria Alice Lahorgue, Carlos Fernando Costa (orgs.). Porto Alegre: Editora da UFRGS, 1999. 
BAPTISTA, Luiz Olavo. Contratos internacionais. São Paulo: Lex Editora; Porto Alegre: Magister, 2011.

BASSO, Maristela. O direito internacional da propriedade intelectual. Porto Alegre: Livraria do Advogado, 2000.

BASSO, Maristela; PRADO, Mauricio Almeida; ZAITZ, Daniela. Direito do comércio internacional: pragmática, diversidade e inovação. Curitiba: Juruá, 2005.

BRASIL. Constituição da República Federativa do Brasil. Brasília: DF, Senado, 1988. Disponível em: 〈www.planalto.gov.br>

BRASIL. Lei 12.259, de 30 de novembro de 2011. Disponível em:

<http://www.planalto.gov.br/ccivil_03/_ato2011-2014/2011/Lei/L12529.htm>. Acesso em: fev. 2015.

CHESBROUGH, Henry. Inovação aberta: como criar e lucrar com a tecnlogia. Tradução: Luiz Claudio de Queiroz Faria. Porto Alegre: Bookman, 2012.

CHESNAIS, Françóis. A mundialização do capital. 1. ed. atual. e ampl. São Paulo: Xamã, 1996.

Convenção da União de Paris. Disponível em: http://www.inpi.gov.br/legislacao-1/cup.pdf. Acesso em: jul. 2015.

CORREAA, Daniel Rocha. Contratos de transferência de tecnologia. Belo Horizonte: Movimento editorial da Faculdade de Direito da UFMG, 2005.

DZEKANIAK, Gisele; ROVER, Aires. Sociedade do Conhecimento: características, demandas e requisitos. DataGramaZero - Revista de Informação - v.12 n.5 out/11. Disponível em: < http://www.dgz.org.br/out11/Art_01.htm>. Acesso em: jul. 2015.

KHAN, Abdul Waheed Khan. Gerência de Informação e Conhecimento/Natura. Entrevista. Disponível em:

<http://xa.yimg.com/kq/groups/16987402/305194573/name/GC_NaturaCosmeticos.pdf>. Acesso em: 20 jul. 2015.

LILLA, Paulo Eduardo. Propriedade Intelectual e Direito da Concorrência - Uma abordagem sob a perspectiva do Acordo TRIPS. São Paulo: Quartier Latin, 2014.

MATTOS, João Roberto Loureiro de; GUIMARÃES, Leonam dos Santos. Gestão da tecnologia e inovação: uma abordagem prática. 2. ed. rev. e atual. São Paulo: Saraiva, 2012.

MUNHOZ, Carolina Pancotto Bohrer. Livre Concorrência e Promoção do Desenvolvimento. In: BARRAL, Welber; PIMENTEL, Luiz Otávio. Propriedade Intelectual e Desenvolvimento. Florianópolos: Fundação Boiteux, 2006.

ORGANIZAÇÃO PARA A COOPERAÇÃO E DESENVOLVIMENTO ECONÔMICO. Manual de Oslo: diretrizes para coleta e interpretação de dados sobre inovação. 3. ed. Rio de Janeiro: FINEP; OCDE, 1997. Disponível em: <http://www.mct.gov.br/upd_blob/0026/26032.pdf>. Acesso em: 15 jul. 2015. 
SILVA, Eduardo Sá. Dicionário de Finanças e Negócios Internacionais. Porto. 2012. Disponível em: <https://books.google.com.br/books?id=Ww8pAwAAQBAJ\&printsec=frontcover\&hl=pt-BR> . Acesso em: 15 jul. 2015.

STRENGER, Irineu. Contratos internacionais do comércio. 2. ed. rev. e ampl. São Paulo: Revista dos Tribunais, 1992.

WACHOWICZ, Marcos. Desenvolvimento Econômico e Tecnologia da Informação. In: BARRAL, Welber; PIMENTEL, Luiz Otávio. Propriedade Intelectual e Desenvolvimento. Florianópolos: Fundação Boiteux, 2006. 